\title{
Santiago Apóstol, una figura mítica en la fiesta de los tastuanes en San Juan de Ocotán, Jalisco.
}

\section{Santiago Apóstol, a mythical figure in the festival of tastuanes in San Juan de Ocotán, Jalisco.}

Cecilia Arriola Montes de Oca

Universidad de Guadalajara (MÉXICO)

CE: ceci.arriola24@gmail.com ID ORCID: 0000-0003-0203-1866

DOI: $10.32870 /$ sincronia.axxiii.n76.37b19

(CC) $\mathrm{BY} \cdot \mathrm{NC}$

Esta obra está bajo una Licencia Creative Commons Atribución-NoComercial 4.0 Internacional

Recibido: $29 / 03 / 2019$

Revisado: $26 / 04 / 2019$

Aprobado: 23/05/2019

\section{RESUMEN}

La construcción de la figura mítica de Santiago Apóstol, a partir de una postura que difiere de la concepción occidental, la cual tiene su base en el mito de las apariciones desde el tiempo de la Colonia, por las pugnas en los diferentes asentamientos de la ciudad de Guadalajara, hasta las apariciones y milagros actuales que los sanjuaneneses piden a Santiago Apóstol, manifestando a través de la recreación anual del mito, en la Fiesta de los Tastuanes.

Palabras clave: Mito. Santiago Apóstol. Fiesta de los Tastuanes.

\section{Abstract:}

The construction of the mythical figure of Santiago Apóstol, from a position that differs from western conception, which has its base in the myth of the appearances from the time of the Colony on the 
struggles in the different settlements of the city of Guadalajara up to the current apparitions and miracles that the people of San Juan ask to Santiago Apóstol, manifesting through the annual recreation of the myth, at the Fiesta de los Tastuanes.

Keywords: Myth. Santiago Apóstol. Fiesta de los Tastuanes.

\section{El mito.}

Durante el siglo XIX surgieron algunos acercamientos al estudio del mito con intención científica, estos se enfocaron en la perspectiva de la cultura occidental y los mitos griegos que emanaban de esta; los cuales fungieron como el patrón de entendimiento de todos los demás mitos, alrededor de ellos se construyó una relación dicotómica entre el logos y el mythos, a fin de entender sus particularidades; generalmente se le definía como lo que no es, no es realidad, no es racional. La concepción de la época no permitía ver al mito más que como "una narración de decadencia moral e intelectual" (Duch, 1998, p. 49). Por mucho tiempo fue este el paradigma del mito, sin embargo esta perspectiva poco podía aportar a la grandiosa producción del mito, presente en casi todas las culturas.

Surge la necesidad de un enfoque más dinámico, alejado de la concepción comparativa y universalista del mito, que predominó en dicha época, que tuviera un acercamiento más real al contexto de donde surgen.

Nos acompañamos en esta aproximación, a la figura de Santiago Apóstol, desde la propuesta de Duch, que entiende al mito como una narración oral con una estructura compleja simbólica, fuerte capacidad de adaptabilidad en constante reinterpretación y resignificación, fincada en un ámbito geo-histórico, que puede llegar a ser un modelo normativo, fundamentador, legitimador de comportamientos (Duch, 1998).

En el contenido de los mitos generalmente vamos a encontrar los orígenes, el principio ya sea de la vida, el universo o incluso el de una cultura o sociedad, o en nuestro caso el principio de un culto; además vamos a encontrar modelos normativos del deber ser, que en muchas ocasiones 
fundamentan el ritual, "los mitos proporcionan el contenido ideológico para las formas de comportamiento sagrado" (Duch, 1998, p.59).

Su trasmisión es una de sus características principales, la oralidad que se comunica de generación en generación; y que con el paso del tiempo se finca y se conserva como, "[...] un patrimonio sagrado de identidad cultural, con ayuda de diferentes artes mnemotécnicas: embellecimiento de situaciones y frases hechas, reforzadas por cadencias musicales, ritmos, danzas [...]" (Barfield, 2007, p. 433). De esta manera, la mitología se entenderá como el estudio, acercamiento o interpretación del mito, que se manifiesta en los relatos orales, con el tiempo van incorporando elementos, por lo cual el mito nunca está acabado de una vez y para siempre (Duch, 1998). Esta evolución, menciona Barfield, obedece a los intereses de las nuevas audiencias, así como para la asimilación de eventos recientes, incorporando diversos sucesos históricos de antigüedad distinta, de ahí que el mito, visto desde una postura rígida resulte incomprensible.

La dificultad de definir el mito, surge de su semejanza con otros conceptos como el de leyenda, ambos están dentro de la tradición oral, son parte del conocimiento tradicional y como tal, son parte del patrimonio cultural, se separan por la fuerza de su profundidad, es decir por la capacidad del mito de dar explicación al origen de algo y en la mayoría de las veces, su acompañamiento de algún ritual o ceremonia religiosa, en un espacio y momento específico; mientras que las leyendas cuentan relatos fantásticos, generalmente con una enseñanza intrínseca, en ella no se habla de dioses, sino de personajes que destacan en acciones especiales, en una mezcla eventos históricos y fantásticos; pero lo más importante es que de las leyendas no surge ceremonia alguna y no requieren ser reproducidas en un espacio sagrado (Villa, 1993).

La leyendas de las apariciones Santiago Apóstol, que se relatan a detalle más adelante, sirven de base a la construcción del mito, debido a la presencia divina de un hombre convertido en santo; las narraciones contienen rasgos de lo que Rudolph Otto denomina como el Mysterium tremendus, el temor que causa la presencia del numen. (Otto, 2008, pp. 31-32).

De esta manera se hace una revisión de la figura de Santiago Apóstol y como esta se va transformando y construyendo a su alrededor un mito, que llega hasta nuestros días. 


\section{Santiago Apóstol}

Nacido en Safra, Saffa ó Yafta, bajo el nombre Jacobo, hijo primogénito de Zebedeo y Salome, hermano de Juan, de familia de pescadores aparentemente prominente, pues son referidos como hijos de Zebedeo, un hombre de importancia en Bethsaida de Galilea, pues contaba con jornaleros en su compañía pesquera. Nombrados por Jesús como Boanerges, hijos del trueno, debido a su carácter apasionado e iracundo. Ambos hermanos se hacen discípulos de Jesús, perteneciendo a su círculo íntimo, junto con Pedro (Cardaillac, 2002).

Tras la muerte de Jesús y su posterior resurrección, relata Antonio López Ferreiro, en su Historia de la Santa A. M. iglesia de Santiago de Compostela, platicó con todos sus discípulos, durante cuarenta días, completando su instrucción religiosa, y les manifiesta su destino, delegándoles su misión y pidiéndoles que esperarán a los diez días, la llegada del espíritu santo para, "[...] que les confortase y les infundiese los dones necesarios con los que pudiesen serle testigos en Jerusalén, Judea y en Samaria y hasta lo último de la tierra" (1898, p. 33).

Los Apóstoles continuaron la conquista espiritual en el mundo, siguiendo las palabras de Jesús, así se repartieron las naciones, a Santiago le correspondió la Península Ibérica. Abandona Judea en el año 32-33, llegando a las costas del reino de Granada, siendo su principal lugar de predicación Iria, “donde más vivas se conservan las memorias de sus hechos" (Ferreiro, 1898, p. 40). En Iria, después llamada Favia, fundó una iglesia y logró la conversión de la poderosa Matrona celta, ó Reina Lupa, quien vivía en una mansión, en lo que hoy es Compostela. Después paso a Astorga, Palencia, Osma, Numancia y Zaragoza, en esta última ciudad, recibió la visita-aparición de la Virgen, cuando está aún vivía, y fundó ahí la iglesia del Pilar.

Después de tres años de estancia en España, regresa a Judea donde continuó realizando conversiones y milagros entre los judíos. Herodes de Agripa en el trono de Judea, lo condenó a ser decapitado en el año 44, tras su muerte sus discípulos recogieron sus restos y los llevaron con Tabitha y Simón, cristianos opulentos que facilitaron los recursos para embalsamarlo y fletar una nave desde el puerto de Joppe a España. Llegaron al puerto de Iria, buscaron protección de la Reina 
Lupa, que anteriormente había aceptado la doctrina del Apóstol, pero su conversión no estuvo completada sin el bautizo; ella se resistió a ayudarlos, por temor a los Druidas y a los romanos, de quien era tributaria. Por lo que los envió ante al subdelegado romano para legalizar la sepultura, pero este los encerró en su calabozo, del cual milagrosamente salieron y huyeron pasando el puente de Nicraria, que se hundió cuando los lanceros romanos los perseguían. Después los discípulos pasaron por el monte de llicino el cual era custodiado por los Druidas celtas y habitado por toros bravos y serpientes peligrosas, invocaron el nombre de Jesús y así los toros obedecieron como mansos corderos, las serpientes cayeron muertas a sus pies y los Druidas quedaron impotentes para perseguirlos, lo que les permitió el paso. Ante esto la reina convencida del poder divino que les asistía, resolvió recibir el bautismo y tomar bajo su protección la sepultura del evangelizador. Así pasaron ocho siglos antes de que el sepulcro captara atención alguna. (Vidal, 1924)

De esta revisión vemos como las leyendas sobre la presencia de Santiago Apóstol, actuaron como un elemento fundamental en la construcción mítica, enfocando pasajes específicos que relatan sus milagros, sin embargo la propagación masiva del culto, por decirlo de algún modo, surge siglos después, en España.

\section{Santiago en España}

El culto de Santiago Apóstol surge a partir de las leyendas que comenzaron a difundirse en la Europa medieval, a partir del hallazgo de los supuestos restos de Santiago Apóstol en el año 820, en Compostela, Galicia. En la época surgen una serie de de documentos como, el Brevarium apostolorum, en el cual se narran las andanzas de los Apóstoles, al proclamar el evangelio por el mundo, en éste Santiago Apóstol aparece como predicador en España.

En el Comentario al Apocalipsis, escrito por el monje Beato de Liébana, refiere a Santiago Apóstol, como fuente de esperanza para los españoles; y es que ante un panorama de crisis política y religiosa, debido a la invasión musulmana, este surgía como una inspiración para los españoles. 
El Codex Calixtinus del Papa Calixto por su parte, que recoge las leyendas y 22 milagros atribuidos a Santiago, en él la figura del santo se va tornando más hacia el tipo guerrero. Más tarde, el siglo XVII se difunde la Leyenda Dorada de Fray Santiago Voragaine, en el que se relata las vidas de los santos, en el capítulo de Santiago escribe sobre su vida, la acción evangelizadora realizada en España, sus milagros en vida y tras su muerte, como el traslado de su cuerpo hasta su sepulcro en Compostela (Cardaillac, 2002).

A través de la influencia de estos textos se propagó el culto y mito de Santiago Apóstol en España, ejercido por los mismos reyes, que peregrinaban a la tumba de Santiago, para solicitar su ayuda en la batallas de recuperación del territorio en manos de los musulmanes. Su primera aparición en batalla, fue en la de Clavijo en el año 844 liderada por Ramiro I, en contra de Abd al Rahman II, que termina en la victoria del ejército español. De esta manera surge la visión de Santiago Apóstol, como el guerrero protector de España, que se le invocaba con el grito de guerra ¡Santiago y cierra España! Pues mientras que en otra partes de Europa la imagen de Santiago era símbolo de peregrinación, en España se transforma en un combatiente de Cristo y en el patrón y señor de España, ante el cual los monarcas acudían a pedir ayuda para la recuperación del territorio. El culto y mito a Santiago Apóstol responde específicamente a la necesidades ideológicas y políticas españolas en los siglos XVII y XVIII (Cardaillac, 2002).

Es decir, en el caso del culto a Santiago encontramos como menciona Duch que:

El mito, como demuestra sobradamente la historia de los pueblos, también realiza funciones histórico-sociales, ya que narra los orígenes del orden actual del ámbito de la naturaleza (creación del mundo) y de la sociedad (historia de una tribu o de un linaje, de una institución, de una evolución social, de una técnica o de un oficio concretos) (1998, p. 88).

Esta concepción del mito que propone Duch, es más extensa y flexible, pues no solo contempla al origen del universo, de la vida en el comienzo del tiempo, también los principios de una sociedad, como lo vemos en el caso del mito de Santiago Apóstol. La propagación de su mito contribuyó a la 
difusión de su culto, que sirvió como base identitaria de la sociedad hispana desde los años medievales en que comienza, hasta después de la conquista del nuevo mundo.

\section{Santiago Apóstol en el nuevo mundo.}

El contacto entre culturas, siempre hace al mundo más grande, o al menos en su contenido, pues al enfrentar la propia cosmovisión a la diversidad resulta un abrupto encuentro de concepciones, ideologías y de construcciones sociales; algo así debió surgir entre los europeos del siglo XVI y los nativos de las Américas. Este es un claro ejemplo de un choque cultural, que se llevó a cabo por varios siglos, en los cuales se dio una serie de enfrentamientos, adaptaciones, sincretismos y uniones en muchos aspectos; el uso de esta palabra, para nada refiere a un acoplamiento armonioso y perfecto.

Este suceso histórico ha sido campo fértil para el estudio antropológico, entre los conceptos que lo han enfocado, está el de aculturación, proceso que sucedió tras la conquista en sus características, de desigualdad, dominación pero también de resistencia; es decir, dentro de los elementos que traía la cultura europea estaba un sistema religioso diferente, esto implicó un proceso de evangelización de la nueva religión, que trajo todo un corpus religioso, creencias, mitos y prácticas. En específico el culto a la figura de Santiago Apóstol, muy popular en España, que significó parte del pensamiento religioso que trajeron consigo los misioneros y conquistadores.

Los primeros encuentros entre españoles e indios se dieron en un contexto de tensión, surgiendo los primeros encuentros bélicos. Sin duda el culto ha sufrido una resignificación considerable, que alude a los procesos sociales, históricos y religiosos que supuso el choque cultural entre la cultura mesoamericana y la europea. Las leyendas de las apariciones de Santo Santiago, construyeron el mito de su culto, y como tal, fue un elemento legitimador en la construcción de la sociedad hispana, en la recuperación del territorio invadido por los musulmanes, y posteriormente para la conquista, es a través de este culto, entre otros, que arranca el proceso de evangelización en el nuevo mundo. 
Para este acercamiento nos enfocamos concretamente a la zona de Occidente, donde se cuentan importantes intervenciones del santo, en favor de los españoles; se hace una revisión de las apariciones descritas en la crónica de Fray Antonio Tello, que construyeron la figura mítica de Santiago Apóstol.

En el año 1530, ante la inminente llegada de las huestes del Capitán Nuño Beltrán de Guzmán a la provincia de Tonalan, los principales de este territorio se reunieron para tratar lo que habían de hacer; tras los temores de lo que el español había hecho en Michoacán, por lo que acordaron, recibirlos en paz. Sin embargo, en la plaza de Tetlán algunos de ellos inconformes, se reunieron para planear la pelea con ellos, diciendo, "ya viene el dios de los tlaxomultecas", de esta manera se juntaron cinco pueblos, los de Tonalán, de Coyotlán, los nahualtecas, chiltecas y tzitlaltecas, salieron al encuentro de los españoles, estos estaban al mando del capitán Nuño de Guzmán, quien a intentó hacer la paz varias veces. Pero al final se dio la batalla,

acometieron y tuvieron una reñida y sangrienta batalla, y en este pueblo los desbarato el Apóstol Santiago á la vista de nuestro ejército y del de los indios, y fue la primera aparición del Santo Apóstol en el reino de la nueva Galicia (Tello, 1984, p. 83-84).

El 12 de Marzo de 1535, acontece una conspiración de indios Caxcanes, Texcuexes y tzacatecos, en Tlacotán, lugar donde Santiago hace su segunda aparición, en la batalla murieron muchos indios, su intervención ayudó al bando español, a salir este peligro (Tello, 1984, p. 223).

Una tercera aparición, antes de la batalla el Br. Bartolomé predicó un sermón para animar los españoles, en cual hace mención de la ayuda que recibirían por parte de San Miguel y Santiago, ya que competían en el bando de los buenos, tal como la batalla que tuvieron los Ángeles contra Lucifer. El primer enfrentamiento en la batalla, surgió a partir de la caída accidental del caballo de Francisco Orozco, quién es atacado por los indios. Inmediatamente después de esto, el gobernador comanda a caballo el ataque diciendo: "Ea, caballeros, vamos todos los de á caballo", y el cogió su caballo y al salir dijo a todos, "Santiago sea con nosotros", relata, que en un instante los repelieron, con la ayuda de Santiago (1984, p. 395-397). 
A las dos de la tarde se juntó todo el campo, y se halló que fueron más de cincuenta mil indios los que vinieron sobre la ciudad, que fue cosa de admiración. Duro la batalla tres horas, y murieron lás de quince mil indios; de los nuestros no falto más que uno, y fue Orozco; y así que llegó y se recogió el campo, todos se fueron por la ciudad á ver sus casas y hallaron en ellas muy gran suma de indios escondidos en los hornos y aposentos, y preguntándoles á que se habían quedado allí, dijeron que de miedo, porque cuando quemaron la iglesia, salió del medio de ella un hombre en un caballo blanco con una capa colorada y cruz en la mano izquierda y en los pechos otra cruz, y con una espada desenvainada en la mano derecha, echando fuego [...], vieron que aquel hombre con su gente andaba entre ellos peleando, y los quemaba y cegaba, y que con este temor se escondieron que le tenían y que muchos quedaron perláticos, y otros mudos. Este milagro representan cada año los indios en los pueblos de la Galicia. (Tello, 1984: 397).

Una cuarta aparición de Santiago a favor de los españoles, se da nuevamente durante un enfrentamiento con los indígenas, en Teúl. El asentamiento es atacado en la víspera de San Miguel, y una vez más aparece el "Apóstol Santiago y á los ángeles, que peleaba en su favor, con que vencieron la barbará nación" (Tello, 1984, p. 237).

En una quinta aparición vencieron en batalla a los indios con la ayuda del Apóstol Santiago, y de P. Fr. Antonio de Segovia en la defensa del cerro del Mixtón.

[...] vio en lo alto del Mixtón un hombre en un caballo blanco con una banderilla en la mano y cruz roja, el cual él dijo: "por ahí es la entrada, soldado", y el Juan Camino subió por un callejón y habiendo llegado junto al del caballo blanco, le dijo: "Llano está esto, arremetemos á los enemigos de Dios. iSantiago y los ángeles sean con nosotros!” y arremetieron á ellos. [...] el virrey estaba comiendo y todo el ejército, y oyeron el tropel y gran ruido que había en lo alto y viendo los enemigos se despeñaron, se armaron todos y fueron a ver [...] el del caballo blanco les dijo: "Por ahí soldados", y entraron todos y vencieron á los que estaban en el Mixtón, y el caballero del caballo blanco se metió en la tropa de los que andana en caballo, y no vieron más (Tello, 1984, p. 465). 
A través de estas apariciones, se construye el mito que da base al culto tan propagado de Santiago Apóstol, en una adaptación del mito fundado en España en los tiempos de la recuperación del territorio de manos de los moros. Teniendo en cuenta esto como fundamento del pensamiento religioso español, el espacio extranjero, el del nuevo mundo era caótico, por lo cual era importante consagrarlo y tomarlo en nombre de Dios, con la ayuda de Santiago Apóstol, para posteriormente ocuparlo.

Un territorio desconocido, extranjero, sin ocupar, (lo que quiere decir con frecuencia: sin ocupar por los nuestros), continua participando de la modalidad fluida y larvaria del caos. Al ocuparlo y, sobre todo, al instalarse en él, el hombre lo transforma simbólicamente en Cosmos, por una repetición ritual de la cosmogonía (Eliade, 1981, p.21).

Este era el pensamiento religioso que predominaba en los tiempos de la colonia, y las acciones de evangelización iban en encausadas a consagrar el nuevo mundo para poder habitarlo. Este proceso de evangelización utilizó muchos otros elementos, además de la reproducción del mito de Santiago, en gran medida se adecuaban a la región, sin embargo este fue muy difundido a través de las Morismas o Danza de moros y Cristianos, en la cual se encontraba presente la figura de Santiago, se realizaba en casi toda la región central de México; entre los totonacas en Veracruz, en Tlaxcala, en las cercanías de la ciudad de México, en Morelos, en Guerrero, Michoacán, Jalisco, Zacatecas y Chihuahua.

[...] un simulacro militar mezclado con diálogos que trata de representar una batalla entre moros y cristianos, divididos en dos grupos antagónicos. Casi siempre es Santiago Apóstol el capitán de los cristianos, así como Pilatos el de los moros (Ricard, 1986, pp. 293-294).

\section{La fiesta de los tastuanes}

Este proceso de evangelización no previó la adaptación de la nueva religión, en una religiosidad popular, donde el mito de Santiago Apóstol fue resignificado, aunque su presencia procede de la coerción que supuso la evangelización, este culto enraizó tan fuertemente que sigue vigente, 
fincado en las leyendas de nuevas apariciones, en sus milagros y manifestado en su fiesta anual de los tastuanes, donde se representa una "danza de conquista" (1996, p., 14-15) desde la perspectiva de Jáuregui y Bonfiglioli, al presentar dos bandos en pugna, por un lado Santiago representando el bando español, pero en la figura de hacendado, y por el otro los tastuanes que representan a los indígenas.

[...] reelaboran su propia cultura, para convertirla en una cultura de conquista. Seleccionaron lo útil, [...] lo que mejor se ajustaba a este nuevo papel, [...] La danza de moros y cristianos, fue seleccionada como parte de la cultura de conquista. No lo fue por ser anónima o ser típica, sino porque desempeñaba un papel dentro del proceso de la conquista (Warman, 1985, p.11).

Actualmente la representación de aquel mito, se reproduce en La fiesta de los tastuanes, una fiesta patronal en honor a Santiago Apóstol, que se celebra cada 25 de julio, con una duración de tres días. Se lleva a cabo en varias localidades de Jalisco, San Juan de Ocotán, Nextipac, Tonalá, Santa Ana Tepetitlán, San Francisco Ixcatán, Jocotán, Zalatitán, así como Apozol y Moyahua en Zacatecas. (Figura 1.).

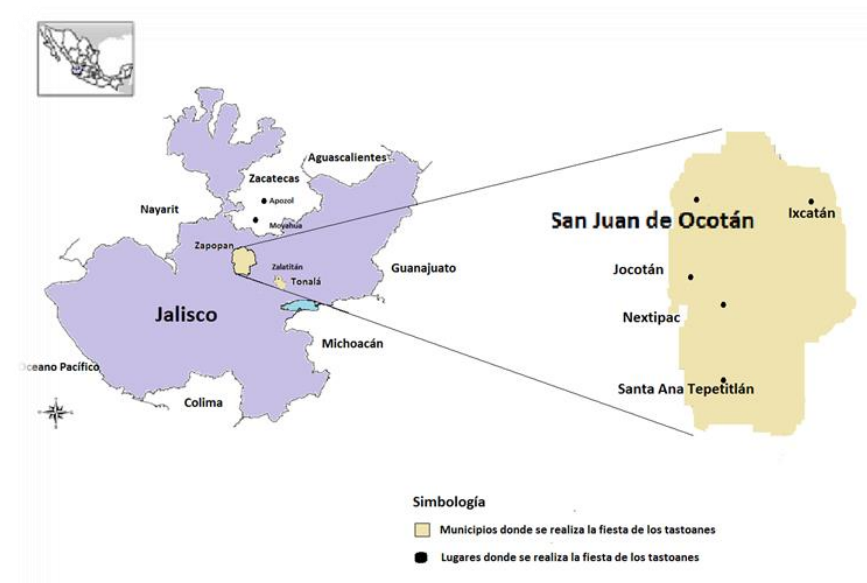

Figura 1. Mapa indicador de las localidades que realizan la fiesta de los tastuanes. (Arriola, 2018, p. XXIII). 
Esta danza lleva el nombre de los icónicos personajes que representan el lado indígena, los tastuanes, esta palabra proviene de la corrupción de Tlatoani, en náhuatl significa el que dice, o el que habla con autoridad, el que manda, así como la presencia de ese personaje en el México mesoamericano (Santoscoy, 1950, p. 22).

Dentro de la danza de los tastuanes en San Juan de Ocotán, hay 21 personajes en la Danza elegida, que hacen la representación en las calles principales de San Juan de Ocotán: el caballero Santiago Apóstol, los Tres Reyes, Sirinero, Capitán Moro, Perrito Rastrero, Tastuan Herodes, Tastuan Pilatos, Tastuan Caifas, Tastuan Anás, Tastuan Firabrás, Tastuan Barrabás, Tastuan Lucifer, el nombre de estos personajes son tomados del Evangelio, como símbolos de oposición a Santiago, además de Tastuan Jilote, Tastuan Elote, Tastuan Ejote, Tastuan Frijol, Tastuan Garbanzo, Tastuan Calabaza, estos otros llevan el nombre de frutos; por último el Tastuan de más, que hace referencia a la participación de los tastuanes del pueblo que no son parte de la danza elegida, pero que participan en los días de fiesta. (Arriola, 2018)

En la danza, ellos representan la medición de las mojoneras, es decir la Hacienda del Cuije y la Hacienda de la Esperanza, que es el territorio que desean y que le pertenece a Santiago Apóstol, pero quien realiza la venta, es el Sirinero como mano derecha de Santiago, este al vender las haciendas a los tastuanes, también vende a Santiago, traicionándolo; el personaje de Tastuan Herodes, es el encargado de darle muerte, cortándole la cabeza y mutilando todas sus partes, mismas que son simuladas con frutos, o comida, que se reparte entre los tastuanes y el pueblo presente en la representación. (Figura 2.)

Después de la matanza de Santiago, Sirinero roba la cabeza del santo, y de esta manera resucita, para castigar a los tastuanes, en las jugadas o cuereadas. (Figura 3.)

Las jugadas o cuereadas, son un enfrentamiento desigual entre el caballero Santiago montado a caballo, contra los tastuanes de más, (Arriola, 2018) que van a pie, estos lo desafían para que los cueree con su espada, esto quiere decir que el Caballero Santiago les pega con la espada en 
cualquier parte de su cuerpo. La participación, por parte de los tastuanes de más, es una de las tantas maneras de pagar manda, ya sea por algún milagro realizado, o para demostrar su fe.

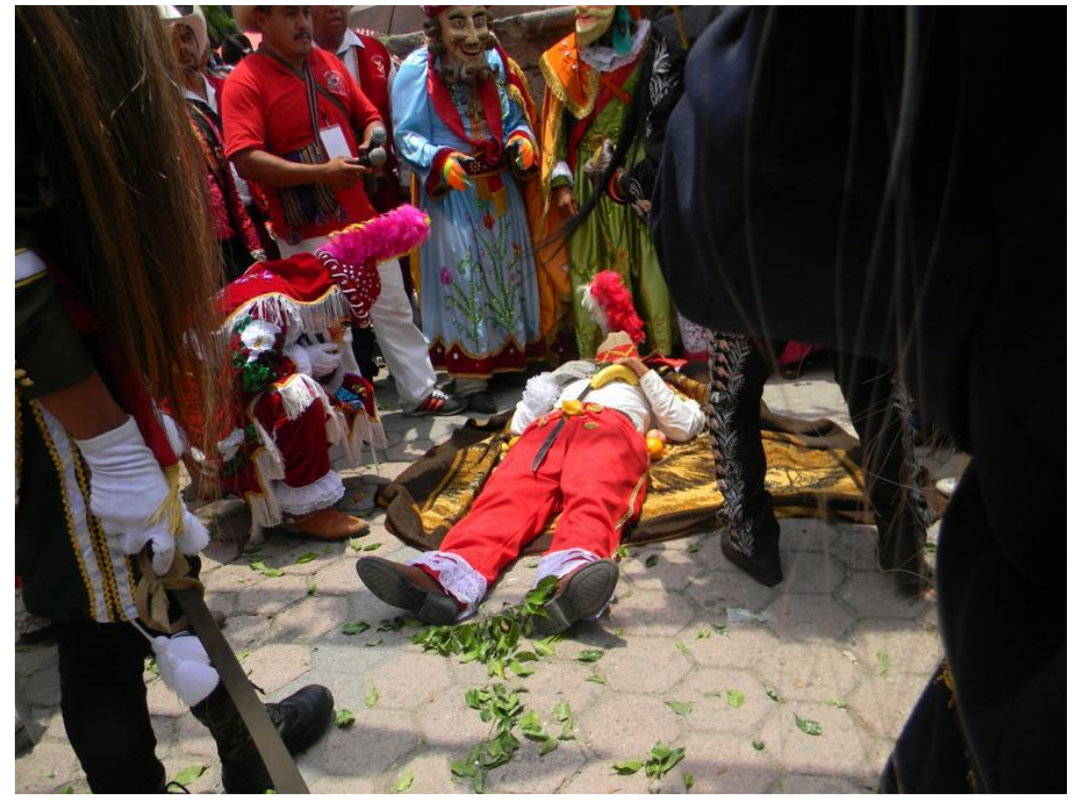

Figura 2. Sirinero llora ante Santiago muerto. San Juan de Ocotán, 2016. (Fotografía propia).

Esta danza se presenta como una combinación de elementos, un sincretismo que tanto nos habla del tiempo de la colonia, como de referencias del Evangelio y situaciones de un contexto más actual, que apuntan a los milagros que le realiza Santiago al pueblo de San Juan de Ocotán.

Aquí la imagen de Santiago sufre una transformación en una especie de inversión del símbolo, es decir que parte de la cosmovisión española de la colonia, como el guerrero que combate con las huestes españolas, a la de un santo que es ejecutado por el bando que representa el bando indígena, y que en su muerte se convierte en un generador de bienes para la comunidad que le mata, a través de la repartición de los frutos que simulan las partes de su cuerpo y además de los milagros que constantemente concede.

Durante la fiesta el carguero que representa a Santiago, el Caballero Santiago, enviste de cierta manera su carácter sagrado, pues además de realizar las jugadas en contra de los tastuanes, 
cuerea a los devotos, dándoles golpes en la espalda con su espada, a los que así lo soliciten y de la manera que lo pidan, lo cual es entendido como manda, o bendición. (Figura 3)

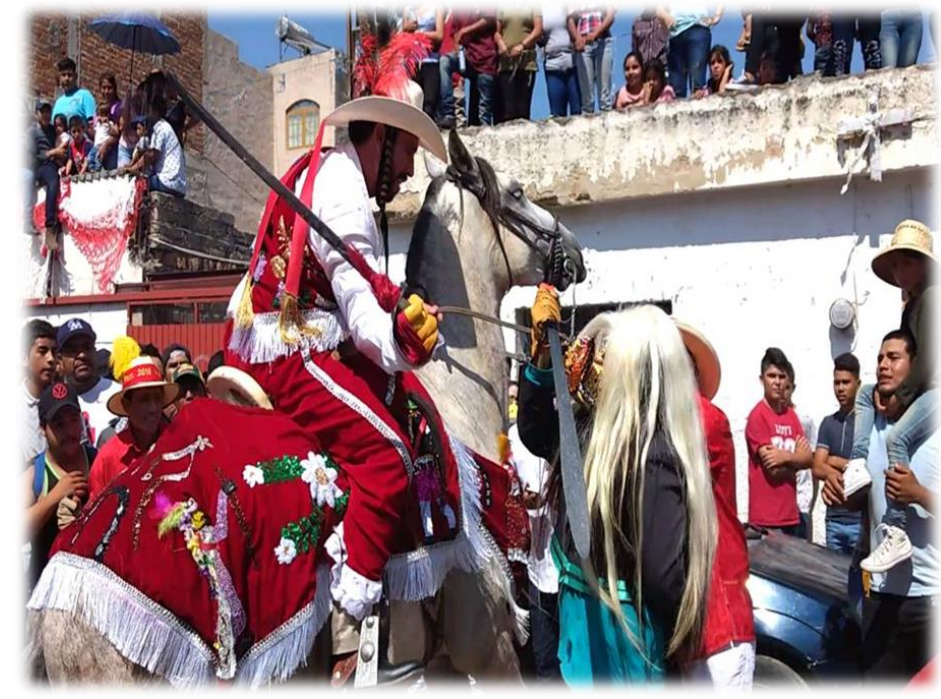

Figura 3. Jugada de la fiesta de los tastuanes, 25 de julio 2018. (Fotografía propia).

Este mismo santo, durante la fiesta recibe innumerables muestras de devoción, la sola participación en cualquiera de los cargos de la cofradía del Santo Santiago representa un acto de manda o de fe, además de la procesión del pago de mandas, en la cual se hace un recorrido de cinco cuadras de rodillas, con ofrendas a la imagen de Santiago Apóstol.

En el último día de fiesta, se pasa el cargo del caballero Santiago, mediante una misa y la última jugada, la manera simbólica que da continuidad al ciclo de la representación del mito de Santiago Apóstol.

\section{La construcción mítica de Santiago Apóstol, en San Juan de Ocotán.}

Existe la creencia de que Santiago Apóstol, cuida de San Juan de Ocotán; entre los peligros que acechan a los sanjuanenses, se encuentra la presencia de la Terminal de Almacenamiento y Distribución (TAD), PEMEX, en la periferia del pueblo, precisamente en la calle de Aviación \# 999. 
Desde su construcción, su presencia ha sido foco de tensión para los habitantes de San Juan de Ocotán, su cercanía y el riesgo que implica, es una preocupación constante. De ello, se manifiestan las historias que narran sobre las apariciones de Santiago Apóstol, para librarles de los riesgos de la TAD, así lo menciona Marco Antonio, Sirinero de la fiesta de los tastuanes del año 2015.

MARCO ANTONIO: lo que mi abuelita siempre nos contaba es que Santiago siempre nos vigila en los linderos, nos vigila, sale, en recorridos en la noche, como...., pues si a cuidarnos, y especialmente cuando queman mucho, porque tenemos PEMEX, aquí en frente, entonces él como que nos cuida de aquel lado, de todos lados pues, pero más enfocado de que en PEMEX no pase nada, porque, entonces mi abuelita, siempre decía, -"desde los linderos nos está cuidando"-, (Entrevista a Marco Antonio Jiménez, Sirinero del 2015, San Juan de Ocotán, 22 julio 2016) .

El peligro de la cercanía de la TAD es una realidad, este es mencionado en el Atlas Municipal de Riesgos por fenómenos Químicos del municipio de Zapopan, Jalisco, como una instalación de alto riesgo, tanto en la actividad como refinería, como por el manejo de sustancias como el diesel y distintos tipos de gasolina. Esto planteado por dicha publicación, como una posibilidad importante de explosión.

En cuanto a la solicitud de los milagros, en su mayoría son en el aspecto de la salud, es decir los sanjuanenses piden a Santiago Apóstol el favor en aquello que el ser humano tiene vetado, el milagro de la salud en los enfermos. Como lo muestra la entrevista realizada a la hija del caballero Santiago del año 2016.

CAMO: ¿Cómo se llama su papá?

NOEMI HUERTA: Bernabé Huerta Carrillo

CAMO: me decía que él pidió la manda

NOEMI HUERTA: pidió la manda a Santo Santiago, pidió la manda por un sobrino que, que hace cinco años se, se cayó de un edificio, de veinticinco metros de altura, y estuvo él, cinco días en, terapia intensiva, pues estaba entubado, y ya no daban, esperanzas pues, ya nada 
mas esperaban el aviso para, que avisaran pues, que ya había fallecido, verdad, y él, nos dijo a nosotros, pues ahí a mi familia, a mi mamá y a mis hermanas, que él iba a ir a misa, y que se iba ya al final, ya que toda la gente se saliera, que para hablar con el santito, Santo Santiago, y que se iba a echar el compromiso, este, primero pues como dicen con el primero, con Dios, fue con el Santísimo y ya de ahí se paso con Santo Santiago y le pidió, pues la manda, que si lo aliviaba él le hacia la fiesta, le hacia su fiesta, y ya desde esa fecha él se anotó. (Entrevista a María Noemí Huerta, San Juan de Ocotán, 10 agosto 2016).

La presencia milagrosa de Santiago, en momentos de peligro es para los sanjuaneneses parte esencial de sus creencias, así lo menciona Alfredo Serrano, Expresidente de la cofradía del Santiago Apóstol, en el siguiente fragmento de entrevista.

ALFREDO SERRANO: bueno, dice mi papá, que cuando yo estaba chico, apenas empezaba a caminar, aquí, pues como le comenté todos son campesinos, todos tenían animales y mi papá tenía unos caballos y me patearon, (...), y no se daban cuenta que el caballo estaba tirando patadas, y a mí me estaba pegando, entonces este, ya cuando se dieron cuenta, ya me daban por, ahora sí que ya por muerto, y le pidieron ayuda Santiago, y bendito sea Dios, aquí estoy (Entrevista al Sr. Alfredo Serrano. San de Ocotán. 23 de Mayo 2012).

Las peticiones que se le hacen Santiago Apóstol, en momentos de urgencia.

MARCO ANTONIO: hay muchas historias también, otra que me contaban también mis abuelos que, una señora, de aquí del pueblo, este, su esposo no llegaba, entonces la señora se encomendó a Santiago, le decía -"tráemelo, tráemelo a espadazos, como sea, pero tráemelo", entonces se apareció la imagen y se le apareció al señor, y pues que se lo trajo correteando en la calle, y el señor pues si decía, -" si se me apareció el caballo blanco". (Entrevista a Marco Antonio Jiménez, Sirinero del 2015, San Juan de Ocotán, 22 julio 2016). 
Este fragmento menciona la imagen de Santiago montado en su leal caballo blanco, que cuida al pueblo del peligro más inmediato. Empero esta imagen converge con la del santo piadoso, que intercede en las peticiones milagrosas, de la salud de los seres queridos.

Para el espectador primerizo, la Fiesta de los tastuanes supone una fiesta sin lógica y sentido, pues en ella parece celebrarse el éxito de la dominación, y como individuos abrazados a nuestras raíces, podemos generar un sentimiento de contrariedad. Asimismo, se puede entender como una fiesta donde revientan excesos, desde lo económico hasta la permisibilidad de romper con los estamentos de la cotidianidad social. Y aunque en definición, así es la fiesta, una ruptura de la cotidianidad, que quiebra los preceptos que imponen las conductas sociales establecidas, (Pérez, 1998), esto no evita los prejuicios que se generan alrededor de ella.

Sin embargo, cuando se nos presenta la oportunidad de acercarnos sin estos juicios de valor, o como investigadores, y nos sumergimos en la cosmovisión de nuestros informantes, encontramos esos elementos que sustentan sus creencias. $Y$ entonces todo gasto, manda, sacrificio, costo y movilización de un pueblo, cobra sentido. (Figura 4)

Figura 4.

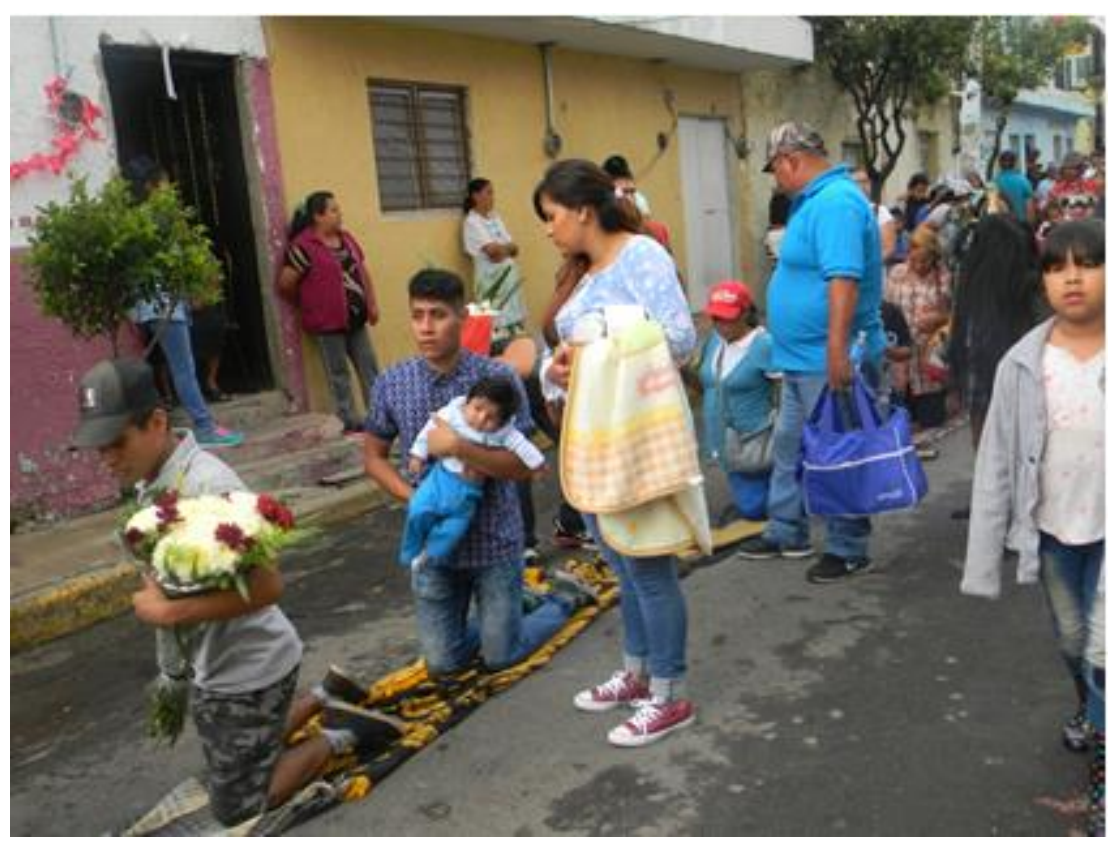

Pago de mandas, Fiesta de los tastuanes, 26 de julio 2016. (Fotografía propia). 
En los fragmentos mencionados, las teofanías, entendidas como la manifestación de lo sagrado, que en su momento consagró el espacio o la acción colonizadora en la llegada española, legitimándola. Con el tiempo, fue el componente principal del relato mítico, que se construyó en una serie de milagros, apariciones y actos divinos realizados por el santo, tanto en la tradición mencionada en la literatura de la Europa medieval, como en sus actuales apariciones e intervenciones entre los habitantes de San Juan de Ocotán. De esta manera se establece la renovación del mito año con año, en una resignificación, que sustenta gran parte del pensamiento religioso actual, en San Juan de Ocotán, con su Fiesta de los tastuanes.

\section{Referencias}

Arriola, C. (2018). Un espacio sonoro llamado la Fiesta de los Tastuanes en San Juan de Ocotán. (Tesis de licenciatura). Universidad de Guadalajara. Guadalajara.

Barfield, T. (2007). Diccionario de Antropología. México: Traducción de Schussheim, V. Siglo XXI.

Cardaillac, L. (2002). Santiago Apóstol: El santo de los dos mundos. México: Colegio de Jalisco.

Consorcio Ambiental y de Servicios S.A. de C.V. (09 de mayo 2019). Atlas Municipal de Riesgos por fenómenos químicos del municipio de Zapopan, Jalisco. Recuperado de https://www.iieg.gob.mx/contenido/GeografiaMedioAmbiente/ATLAS\%20FENOMENOS\%20QUIMIC OS\%20ZAPOPAN\%202009.pdf

Duch, L. (1998). Mito, Interpretación y Cultura. Herder. España.

Eliade, M. (1981). Lo Sagrado y lo Profano. Cuarta edición. Trad. Luis Gil. Guadarrama, Punto Omega.

Madrid. Recuperado 24 junio de 2018, de

https://antroporecursos.files.wordpress.com/2009/03/eliade-m-1957-lo-sagrado-y-lo-profano.pdf

Jáuregui, J. y Bonfiglioli C. (1996). La danzas de la conquista. México Contemporáneo. México: Fondo de Cultura Económica. 
López, A. (1898). Historia de la Santa A. M. iglesia de Santiago de Compostela. España. Ed.: Seminario Conciliar Central. Recuperado 10 de agosto de 2018 de https://archive.org/details/historiadelasanta01lpez

Otto, R. (2008). Lo Sagrado, 1ạ edición. Buenos Aires. Claridad.

Pérez, H. (1998). La Fiesta en México. En Pérez Martínez, H. México en fiesta. México: Colegio de Michoacán, pp. 11-65.

Tello, A. (1984). Crónica miscelánea de la sancta provincia de Xalisco, LII (I). México: IJAH.

Ricard, R. (1986). La conquista espiritual de México. Ensayo sobre el apostolado y los métodos misioneros de las órdenes mendicantes en la Nueva España de 1523-1524 a 1572. México: FCE.

Santoscoy, A. (1950). Los tastoanes: estudio etnográfico histórico. Mexico: tip. de J. G. Montenegro.

Vidal R. M. (1924). La tumba del Apóstol Santiago. España. Seminario C. Central.

Villa P. E. (1993). Mitos y Leyendas de Colombia, I. Colombia. IADAP.

Warman. A. (1985). La danza de Moros y cristianos. Segunda edición. México. INAH. 